\title{
Pathogenesis of Type 2 (non-insulin-dependent) diabetes mellitus: the role of skeletal muscle glucose uptake and hepatic glucose production in the development of hyperglycaemia. A critical comment
}

\author{
H. Beck-Nielsen ${ }^{1}$, O. Hother-Nielsen ${ }^{1}$, A. Vaag ${ }^{1}$, F. Alford ${ }^{2}$ \\ ${ }^{1}$ Department of Internal Medicine M, Odense University Hospital, Odense, Denmark \\ ${ }^{2}$ Department of Endocrinology, St. Vincent's Hospital, Melbourne, Australia
}

The pathogenesis of Type 2 (non-insulin-dependent) diabetes mellitus has recently been debated $[1,2]$. The basis of the controversy centres around the roles of glucose production by the liver and its sensitivity to insulin, and glucose uptake by skeletal muscle in the development of hyperglycaemia. Most investigators agree that the three major players in the genesis of diabetic hyperglycaemia are the "triumvirate"; betacell function, insulin-mediated glucose uptake (GU) (in skeletal muscle predominantly) and hepatic glucose production (HGP). But the relative importance of these three variables, with respect to time course, quantity and quality in the development of diabetes forms the basis for the disagreement. Overproduction of glucose by the liver (secondary to hepatic insulin resistance or reduced insulin secretion or both) has been postulated to be the primary and quantitatively most important defect in Type 2 diabetes [1]. In other studies HGP was found to be normal in glucose intolerant individuals with normal or near-normal fasting glycaemia of $7.8 \mathrm{mmol} / \mathrm{l}$ or less [2], at which time insulin resistance is already clearly demonstrable [2]. Based on that reduced insulin-mediated glucose uptake in skeletal muscle was postulated to be the primary defect, and hyperglycaemia (i.e. $>7.8 \mathrm{mmol} / \mathrm{l}$ ) was found to appear once insulin secretion starts to deteriorate and HGP to increase [2]. In several studies a positive correlation between HGP and fasting plasma glucose concentrations has been claimed to take place in Type 2 diabetic subjects, and used to support the argument that increased HGP plays a key role in the development of progressive hyperglycaemia i.e. diabetes $[1,2]$.

However, our previous [3, 4] and more recent data (Fig.1) fail to demonstrate this positive correlation be-

Corresponding author: Professor H. Beck-Nielsen, Department of Internal Medicine M, Odense University Hospital, Sondre Boulevard, DK-5000 Odense C, Denmark tween HGP and fasting plasma glucose (for glucose levels 5 to $12-15 \mathrm{mmol} / \mathrm{l}$ ) which we believe is due to important methodological problems inherant to the calculation of HGP in hyperglycaemic states in previous studies $[4,5]$. Given the potential importance of these methodological aspects to the measurement of HGP and the central role placed on HGP by the other debators, we have decided to enter this discussion in order to emphasize the importance of the methods used to calculate HGP. We also want to point out that the results of glucose metabolism from skeletal muscle are much less controversial than the HGP data, since tracer data and direct measurements of glucose uptake across the muscle by arterio-venous (A-V) differences, using arm and leg preparations, plus in vitro muscle biopsy studies, have all corroborated the presence of insulin resistance in Type 2 diabetic subjects [6-8].

Thus, in this commentary we will discuss some of the general questions raised in the debate but will mainly focus on the methodological problems that arise in estimating HGP, and how these may impact on the final interpretation of kinetic data. Furthermore, we will present data supporting our hypothesis concerning the de-

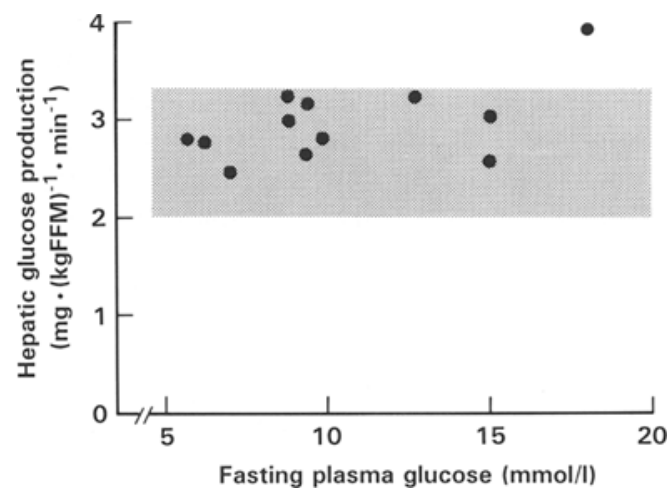

Fig.1. Correlation between hepatic glucose production and fasting plasma glucose in 12 Type 2 diabetic patients. Calculated from previously published data [5] with permission 
velopment and pathophysiological role of hyperglycaemia in Type 2 diabetes - "the compensatory role of hyperglycaemia".

\section{The concept of elevated basal glucose production in Type 2 diabetes}

As stated above, increased basal HGP has been postulated to be a characteristic feature of patients with Type 2 diabetes [1,2]. In passing, it should be noted that DeFronzo and co-workers [2] found normal HGP levels in subjects with normal to and slightly elevated fasting plasma glucose levels $(<7.8 \mathrm{mmol} / 1)$, where renal glucose loss is likely to be negligible in the majority of subjects. However, they found elevated HGP ( $>2.2 \mathrm{mg} \cdot \mathrm{kg}^{-1} \cdot \mathrm{min}^{-1}$ ) in only 9 of 27 individuals whose fasting blood glucose levels ranged between 7.9 and $10 \mathrm{mmol} / \mathrm{l}$. Nevertheless, many authors use this positive correlation to emphasize the importance of an increase in HGP for the development of hyperglycaemia and diabetes. However, we question this conclusion given the fact that we have not been able to confirm the presence of significantly raised HGP in diabetic subjects with fasting blood glucose levels below 12-15 $\mathrm{mmol} / \mathrm{l}[3,9-11]$. In our most recent study, we found HGP to be near normal (increased by only about $10 \%$ ) in Type 2 diabetic patients without glycosuria (blood glucose $<15 \mathrm{mmol} / \mathrm{l}$ ) and not to be related to the level of fasting hyperglycaemia [4,5] (Fig. 1). These findings are in agreement with some previous studies.

If HGP is supposed to be increased in Type 2 diabetic subjects (without glycosuria), glucose uptake in peripheral tissues must be elevated to the same degree if fasting glucose remains constant from day to day, i. e. subjects are at steady state. If such a steadystate condition was not reached, glucose concentrations would continuously increase. Since this is not the case in the majority of Type 2 diabetic subjects, the question arises: where is the increased glucose produced by the liver going to in these individuals? This question has not been answered as yet. Most glucose in the basal state is taken up and oxidized in the central nervous system (CNS) but some glucose is also taken up in the splanchnic bed and in skeletal muscle. Basal glucose oxidation (measured at the prevailing hyperglycaemic level) has been found to be normal in Type 2 diabetic subjects when estimated by indirect calorimetry $[4,8,12-14]$. Glucose uptake in the splanchnic bed is also normal [6]. Glucose uptake in skeletal muscles, as measured by A-V glucose differences in the arm and leg, has usually been found to be close to normal or slightly increased under the prevailing hyperglycaemia $[7,15]$. In the most recent study, glucose uptake in the leg of Type 2 diabetic subjects was found to be slightly but not statistically significantly increased, being approximately $0.16 \mu \mathrm{mol} / 100 \mathrm{ml}$ muscle tissue per minute higher than in normals, corresponding to a whole body difference of about $0.12 \mathrm{mg} \cdot \mathrm{kg}^{-1} \cdot \mathrm{min}^{-1}$ (estimated on the basis of a body weight of $80 \mathrm{~kg}$ and a muscle mass of $32 \mathrm{~kg}$ ). This figure matches the about $10 \%$ increase in HGP found in our diabetic subjects (Fig. 1). Given the fact that glucose uptake in the brain of Type 2 diabetic subjects is normal or even possibly slightly reduced, it would not explain the 0.5 to $2.0 \mathrm{mg} \cdot \mathrm{kg}^{-1}$. min $^{-1}$ increases in HGP reported in several other studies [4]. Thus, these normal or near-normal rates of glucose uptake obtained with catheterisation and direct measurements of $\mathrm{A}-\mathrm{V}$ differences and the results of indirect calorimetry, indicate that the raised HGP levels obtained by the isotope dilution technique in several previous studies may represent an overestimation of HGP.

What is the reason for this?

\section{Problems in tracer methodology (basal state)}

When reviewing previous studies where HGP had been measured in Type 2 diabetic subjects using the primed ${ }^{3} \mathrm{H}$-glucose infusion technique, marked differences in glucose production rates were reported, ranging from normal through to $240 \%$ of normal [4]. In those studies where the investigators reported the highest elevation of HGP a fixed priming dose of tritiated glucose was used, regardless of the basal blood glucose level present at the time of study. In contrast, in those studies which documented normal or near-normal HGP values, the priming dose of ${ }^{3} \mathrm{H}$-glucose was adjusted to the prevailing fasting blood glucose concentration. In these latter studies a constant steady-state level of plasma $3-{ }^{3} \mathrm{H}$-glucose specific activity was obtained after about $1 \mathrm{~h}$ with the "adjusted" priming technique, whereas with the "fixed" priming method steady state was not approached, i.e. both tracer concentration and specific activity were still increasing after $6 \mathrm{~h}$. Thus, only with the adjusted priming technique is a plateau steady-state situation reached which therefore permits glucose turnover to be calculated from the simple ratio of tracer infusion rate and the specific activity in plasma [4]. With the fixed prime, an ongoing rise in tracer specific activity in plasma occurs and plasma specific activities remain low, which together leads to the calculated glucose turnover rates being too high. This error will be greater in those studies with the highest fasting blood glucose level; it is not surprising that in these latter situations, the level of glucose turnover (HGP) will correlate positively with the fasting blood glucose level. An additional source of error in the majority of previous studies is the assumption that glucose appearance and glucose disappearance are equal in the fasting postabsorptive state in Type 2 diabetic subjects. This is incorrect since plasma glucose is declining in time over $6 \mathrm{~h}$, at a rate of $0.52 \mathrm{mmol} \cdot \mathrm{l}^{-1} \cdot \mathrm{h}^{-1}[4,16,17]$. Therefore if $\mathrm{HGP}$ is calculated by dividing the tracer infusion rate with the specific activity of the tracer (i.e. assuming a 
steady-state situation), HGP will be overestimated. On the other hand, if Steele's non-steady-state equations are employed, a lower estimate of HGP will result [4].

In Figure 2, we have shown the correlation between fasting plasma glucose values and glucose turnover calculated by using the steady-state equation (upperpanel) and HGP as calculated using Steele's non-steady-state equation (lower panel), respectively. Results from the adjusted and the fixed priming method are also given. The data clearly show that HGP in Type 2 diabetic subjects is normal or near normal, when measured using adjusted prime and Steele's non-steady-state equations. Furthermore, there is not a positive correlation between HGP and fasting blood glucose values at fasting blood glucose levels of less than $15.0 \mathrm{mmol} / \mathrm{l}$. This was confirmed in both obese and lean subjects. Thus, we may conclude that HGP may have been overestimated in most previous studies to a variable extent. The correlation observed between fasting blood glucose and HGP, which has been used to emphasize the importance of the overproduction of glucose by the liver in the development of hyperglycaemia should be seriously questioned. Admittedly, when significant glycosuria develops (in those patients at plasma glucose levels of about $10-15 \mathrm{mmol} / \mathrm{l})$, HGP may rise to compensate for the glucose spillover.

\section{Is the liver insulin resistant in Type 2 diabetic patients?}

The euglycaemic clamp employing the infusion of unlabelled "cold" glucose in combination with a tracer infusion has traditionally been used to measure rates of glucose production and utilisation in response to insulin. It has been, however, clearly documented that with this conventional approach of constant tracer and unlabelled glucose infusions, rates of glucose appearance are underestimated $[18,19]$. Consequently, insulin stimulation of glucose utilisation has been underestimated and insulin suppression of glucose production overestimated. Because previous studies have infused unlabelled glucose it is therefore likely that glucose utilization is more sensitive to insulin and glucose production less sensitive than previously assumed. Furthermore, as errors are greater the greater the glucose infusion rate, mistakes may have been greatest in normal control subjects requiring large glucose infusions and smaller in resistant Type 2 diabetic patients requiring smaller glucose infusions [19]. This means that previous studies may have underestimated peripheral insulin resistance and overestimated hepatic insulin resistance in Type 2 diabetic patients. Thus, to adequately assess glucose turnover rates during combined infusions of glucose, insulin and tracer, future studies will require maintenance of unchanged plasma specific activities by the co-infusion of labelled glucose infusate ("Hot-GINF") during the clamps $[18,19]$. The well-known but often overlooked problem of negative HGPvalues during the infu-
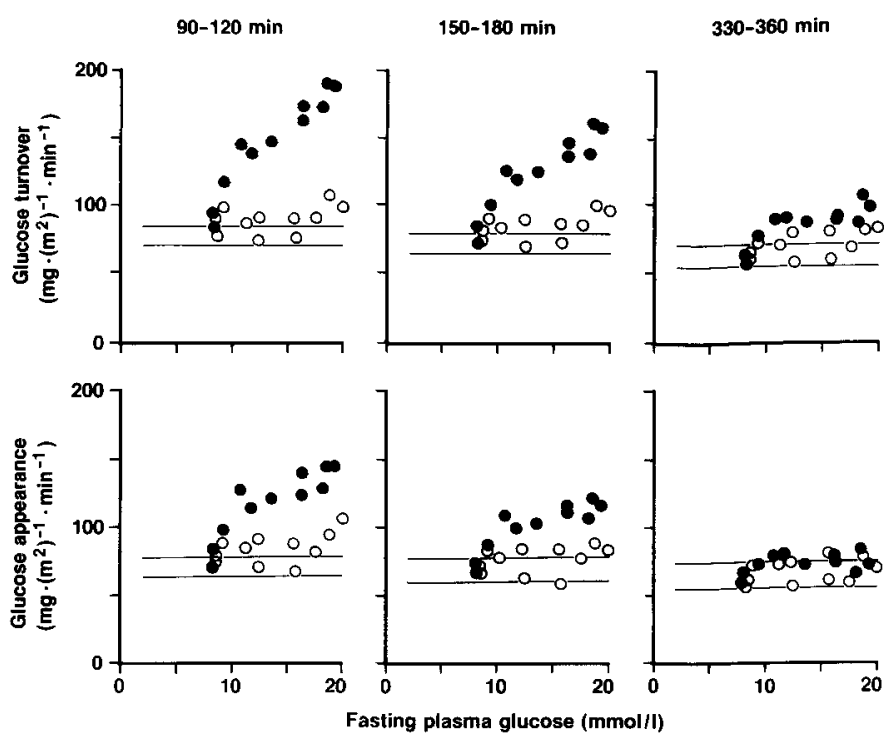

Fig. 2. Correlation between plasma glucose concentration and glucose turnover rate (GT) (upper panel) after 90-120, 150-180 and 330-360 min tracer infusion in 11 Type 2 diabetic patients using fixed (O) or adjusted (O) primed-continuous $3-{ }^{3} \mathrm{H}$-glucose infusion. Mean \pm SD of seven non-diabetic control subjects are indicated by horizontal lines. Using fixed priming the correlation of both glucose turnover (GT) and glucose appearance rate (RA) to plasma glucose concentration decreased in time (GT: $r=0.97,0.97,0.86$, all $p<0.01$, RA: $r=0.91,0.88$, both $p<0.01$, and $r=0.37, p=N S)$. Using adjusted priming no correlation was found (GT: $r=0.49,0.51,0.46, \mathrm{RA}: r=0.47,0.31,0.14$, all $p=$ NS). Reprinted with permission [4]

sion of cold glucose will also be resolved. No data in Type 2 diabetes are as yet published with the "HotGINF" technique and therefore it is impossible to conclude at the present time, if the liver is resistant to infusions of low dose insulin in these patients. However, given the fact that HGP is normal or only slightly raised in normo- and hyperglycaemic Type 2 diabetic subjects in the presence of raised basal endogenous insulinaemia $[3,4]$, it is possible that the liver is resistant to insulin in Type 2 diabetes. By contrast, in cirrhotic subjects with known severe insulin resistance and marked fasting hyperinsulinaemia, HGP is significantly reduced compared to normal control subjects indicating normal hepatic insulin sensitivity in the latter subjects [20]. Thus, the final discussion of the role of hepatic insulin resistance in Type 2 diabetes and the comparison with insulin resistance in skeletal muscles must await future investigations with more accurate methods.

\section{Where is the primary (genetic) insulin resistance located - in muscle or liver?}

Skeletal muscles in Type 2 diabetic subjects are insulin resistant. The ability of insulin to stimulate glucose disposal in Type 2 diabetic subjects has been localised to a reduction in glycogen synthesis (so called "glucose 

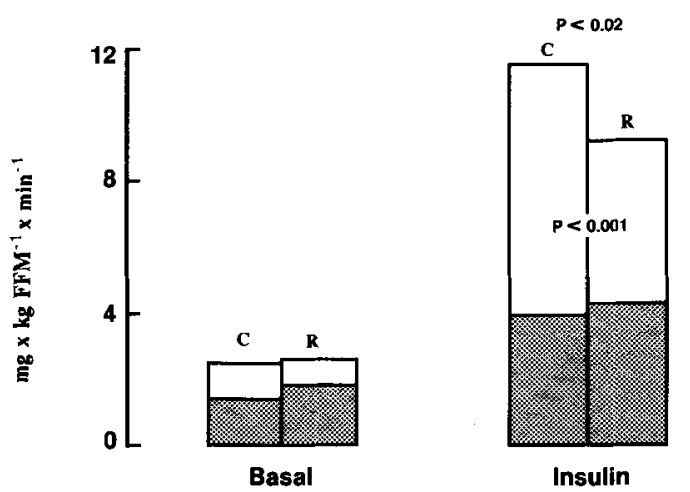

Fig. 3. Insulin-mediated glucose uptake in peripheral tissues in young first degree relatives $(R)$ to Type 2 diabetic patients and in control subjects (C). Reprinted with permission from [22]. Glucose oxidation; $\square$, non-oxidative glucose metabolism. FFM, Fat free mass

storage") [21]. This has been found uniformly with in vivo tracer as Nuclear Magnetic Resonance (NMR) methodologies, and by in vitro studies with muscle biopsies which show reduced intracellular glycogen synthase activity (the key enzyme in glycogen synthesis), accumulation of free glucose and possibly glucose 6phosphate [12]. However, it has not been possible to decide whether these defects are of primary or secondary origin. Of much greater significance therefore, would be evidence of insulin resistance being present in individuals before the development of frank diabetes. The investigation of normal glucose tolerant first degree relatives of Type 2 diabetic subjects (i.e. probands with two parents or one parent and one sibling with the disease), of whom about $40-50 \%$ will develop frank diabetes, proved critical in determining whether insulin resistance could be a primary inherited defect. Thus, studies of these normal glucose tolerant relatives have shown that approximately $40 \%$ of such individuals are insulin resistant and that the insulin resistance is located at the level of glycogen synthesis in their skeletal muscles (Fig. 3) [22]. Of interest, basal HGP [22, 23] and the inhibitory effect of insulin on HGP was found to be normal in these subjects, indicating that the primary (genetic?) insulin resistance must be located in skeletal muscles and not in the liver [24].

\section{The "compensation" theory}

In hyperglycaemic Type 2 diabetic subjects, we and others have found normal or near-normal glucose turnover in the post-absorptive state, despite the prevailing higher glucose and insulin levels in these subjects. Such data would suggest that the hyperglycaemia and hyperinsulinaemia are necessary to "compensate" for the cellular defects in insulin action. From our studies, plasma glucose levels appear to rise to exactly the level necessary to compensate for the reduction in the processing of cellular glucose in peripheral tissues $[3,12]$.
Glucose is taken up in muscles by a mass action effect (as well as the insulin-stimulated pathways) and this mass action of hyperglycaemia may compensate for the reduction in insulin-mediated glucose uptake. We would therefore suggest that the rise in plasma glucose is matched to the need to normalize glucose disposal in these insulin-resistant diabetic individuals. In support of this hypothesis, we, and others, have found that glycogen synthesis and glycogen synthase activity in skeletal muscles are normalised by hyperglycaemia and hyperinsulinaemia (thereby compensating for the insulin resistance). The mechanism by which hyperglycaemia and hyperinsulinaemia overcome the insulin resistance is not totally unveiled at this stage but from our in vitro muscle biopsy studies it appears that the defect in covalent activation of glycogen synthase activity is compensated for by both an increase in allosteric activation of the enzyme itself, and by an as yet incompletely understood permissive effect of glucose on the covalent activation [12].

These findings indicate to us that the organism aims to keep glucose turnover within normal range. For this to occur insulin resistance must be compensated for e.g. by hyperinsulinaemia in the pre-diabetic and by hyperglycaemia in the diabetic state. If this compensation procedure is complete, then glucose turnover and thereby HGP will continue to be normal or near normal. The mechanism responsible for this communication between skeletal muscle and the liver is unknown but may be an increase in glycolysis in the muscle (due to reduced glycogen storage) resulting in an increased lactate/alanine supply to the liver. This substrate supplementation will increase gluconeogenesis, as previously shown [1]. Thus, HGP can be kept normal (autoregulation) despite hyperinsulinaemia and hyperglycaemia, which is known to suppress glycogenolysis [25]. Following this hypothesis (which has not been proven) the degree of insulin resistance in skeletal muscle determines the rate of glycolysis and thus also in part the rate of HGP.

\section{Conclusion}

Our understanding of the pathophysiology of Type 2 diabetes has advanced considerably over the last decade, but many problems and issues remain unresolved. The initiation of this debate mirrors many of the problems that we face today. An understanding of the primary and secondary defects leading to diabetes in "genetically prone" individuals are of crucial importance to further our understanding of the metabolic process involved in the development of the diabetic state. In our contribution to this debate we have pointed out the methodological problems that have arisen in the estimation of HGP and the quantitation of glucose kinetics in normo- and hyperglycaemic Type 2 diabetic individuals. These problems are not yet com- 
pletely resolved. Therefore, the importance of the liver vs the importance of muscle glucose metabolism in the development of hyperglycaemia will probably have to wait for new and improved techniques. However, the current data strongly indicate that the primary defect (genetic defect?) in insulin action is located to skeletal muscles.

The near-normal HGP values in Type 2 diabetes patients with fasting blood glucose values less than 12 $15 \mathrm{mmol} / \mathrm{l}$ do not indicate that the insulin sensitivity of liver is normal in Type 2 diabetes, but proves to us that the reduction in insulin action in both liver and muscles are fully compensated - perhaps slightly overcompensated.

\section{References}

1. Gerich JE (1991) Is muscle the major site of insulin resistance in type 2 (non-insulin-dependent) diabetes mellitus? Diabetologia 34: 607-610

2. DeFronzo RA (1992) Pathogenesis of type 2 (non-insulindependent) diabetes mellitus: a balanced overview. Diabetologia 35:389-397

3. Hother-Nielsen O, Beck-Nielsen H (1991) Insulin resistance, but normal basal rates of glucose production in patients with newly diagnosed mild diabetes mellitus. Acta Endocrinol (Copenh) 124: 637-645

4. Hother-Nielsen O, Beck-Nielsen H (1990) On the determination of basal glucose production rate in patients with type 2 (non-insulin-dependent) diabetes using primed-continuous 3- ${ }^{3} \mathrm{H}$-glucose infusion. Diabetologia 33: 603-610

5. Vaag A, Skött P, Damsbo P, Gall M-A, Richter EA, BeckNielsen H (1991) Effect of anti-lipolytic nicotinic acid analogue acipimox on whole body and skeletal muscle glucose metabolism in patients with non-insulin-dependent diabetes mellitus. J Clin Invest $88: 1282-1290$

6. DeFronzo RA, Gunnarson R, Bjorkman O, Olsson M, Wahren J (1985) Effects of insulin on peripheral and splanchnic glucose metabolism in non-insulin-dependent (type II) diabetes mellitus. J Clin Invest 76: 149-155

7. Capaldo B, Napoli R, DiMarino L, Picardi A, Riccardi G, Sacca L (1988) Quantitation of forearm glucose and free fatty acid (FFA) disposal in normal subjects and type II diabetic patients: evidence against an essential role for FFA in the pathogenesis of insulin resistance. $\mathrm{J}$ Clin Endocrinol Metab 67: 893-898

8. Damsbo P, Vaag A, Hother-Nielsen O, Beck-Nielsen $\mathbf{H}$ (1991) Reduced glycogen synthase activity in skeletal muscle from obese patients with and without type 2 (non-insulin-dependent) diabetes mellitus. Diabetologia 34: 239-245

9. Hother-Nielsen O, Beck-Nielsen H (1991) Basal glucose metabolism in type 2 diabetes: a critical review. Diabete Metab 17: $136-145$

10. DeFronzo RA, Simonson D, Ferrannini E (1982) Hepatic and peripheral insulin resistance: a common feature of type 2 (non-insulin-dependent) and type I (insulin-dependent) diabetes mellitus. Diabetologia 23: 313-319
11. Hother-Nielsen O, Schmitz O, Andersen PH, Pedersen O, Beck-Nielsen $H$ (1988) In vivo action of glibenclamide in obese subjects with mild type 2 (non-insulin-dependent) diabetes. Diabetes Res 8: 63-70

12. Vaag A, Damsbo $P$, Hother-Nielsen O, Beck-Nielsen $\mathbf{H}$ (1992) Hyperglycaemia compensates for the defects in insulin-mediated glucose metabolism and in the activation of glycogen synthase in the skeletal muscle of patients with type 2 (non-insulin-dependent) diabetes mellitus. Diabetologia 35: $80-88$

13. Boden G, Ray JK, Smith RH, Owen OE (1983) Carbohydrate oxidation and storage in non-insulin dependent diabetic patients. Diabetes 32: 982-987

14. Felber JP, Ferrannini E, Golay A et al. (1987) Role of lipid oxidation in the pathogenesis of insulin resistance of obesity and type II diabetes. Diabetes 36: 1341-1350

15. Kelley D, Mandarino L (1990) Hyperglycemia normalizes insulin-stimulated skeletal muscle glucose oxidation and storage in noninsulin-dependent diabetes mellitus. J Clin Invest 86: 1999-2007

16. Glauber H, Wallace P, Brechtel G (1987) Effects of fasting on plasma glucose and prolonged tracer measurement of hepatic glucose output in NIDDM. Diabetes 36: 1187-1194

17. Chen Y-DI, Swislocki ALM, Jeng C-Y, Juang J-H, Reaven GM (1988) Effect of time on measurement of hepatic glucose production. J Clin Endocrinol Metab 67: 1084-1088

18. Finegood DT, Bergman RN, Vranic M (1987) Estimation of endogenous glucose production during hyperinsulinemiceuglycemic glucose clamps. Comparison of unlabeled and labeled exogenous glucose infusates. Diabetes 36: 914-924

19. Hother-Nielsen O, Mengel A, Møller J, Rasmussen O, Schmitz O, Beck-Nielsen H (1992) Assessment of glucose turnover rates in euglycaemic clamp studies using primedconstant $\left[3-{ }^{3} \mathrm{H}\right]$-glucose infusion and labelled or unlabelled glucose infusates. Diabetic Med 9: 840-849

20. Proietto J, Alford FP, Dudley FJ (1980) The mechanism of carbohydrate intolerance of cirrhosis. J Clin Endocrinol Metab 51: 1030-1036

21. Beck-Nielsen H, Vaag A, Damsbo P et al. (1992) Insulin resistance in skeletal muscles in patients with NIDDM. Diabetes Care 15: 418-429

22. Vaag A, Henriksen JE, Beck-Nielsen H (1992) Decreased insulin activation of glycogen synthase in skeletal muscles in young nonobese caucasian first-degree relatives of patients with non-insulin-dependent diabetes mellitus. J Clin Invest 89: 782-788

23. Eriksson J. Franssila-Kallunki A, Ekstrand A et al. (1989) Early metabolic defects in persons at increased risk for noninsulin-dependent diabetes mellitus. N Engl J Med 6: 337343

24. Gullig, Ferrannini E, Stern M, Haffner S, DeFronzo R (1992) The metabolic profile of NIDDM is fully established in glucose-tolerant offspring of two Mexican-American NIDDM parents. Diabetes 41: 1575-1586

25. Magnusson I, Tothman LD, Katz L, Shulman RG, Shulman GI (1992) Increased rate of gluconeogenesis in type II diabetes mellitus. J Clin Invest 90: 1323-1327 